\title{
PSICOHISTORIA Y FORMAS HISTÓRICO GENERALES DE LA PERSONALIDAD EN EL PERÚ
}

\author{
Santiago Paredes Ruiz ${ }^{1}$ \\ Universidad Nacional Mayor de San Marcos, Perú \\ (RECiBido El 07/11/2007, ACEPTADO EL 30/05/2008)
}

\section{RESUMEN}

El presente artículo es una síntesis de las investigaciones teóricas y metodológicas de las formas histórico generales de la personalidad en el Perú, esto es desarrollado desde los campos de la psicohistoria y neurociencias. Se plantea y desarrolla la categoría de formas histórico generales de la personalidad. Se explica su devenir en la evolución de los hombres del Perú, desde la época prehispánica hasta el período republicano, incluyendo la Colonia. Los datos históricos y sociales de cada época se integran dentro de una interpretación psicológica de los patrones más generales de personalidad. Seguimos un método de análisis cualitativo a partir de datos históricos. Desde una reelaboración psicohistórica, interrelacionamos e integramos construcciones transdisciplinarias, neurocientíficas, psicológicas, históricas y etnohistóricas. En las conclusiones, resaltamos el valor heurístico de la categoría formas histórico generales de la personalidad, para el desarrollo de la psicohistoria, de la psicología, y de las neurociencias de base científico social.
\end{abstract}

Palabras clave: Formas histórico generales de la personalidad, Esencia humana, personalidad, Psicohistoria, Neurociencia, Etnohistoria, Dualidad histórica.

\begin{abstract}
The present paper is a synthesis of the theoretical and methodological investigations about the general historical forms of personality in Peru, which is developed from the fields of psychohistory and neurosciences. We propose and develop the category of general historical forms of personality. We explain their development in the evolution of people from Peru, from the prehispanic time, until the republican period, including the colony. The historical and social data of each time are integrated inside a psychological interpretation of the most general patterns of personality. We follow a method of qualitative analysis starting from historical data. From a psychohistoric restructuring, we interrelate and integrate transdisciplinary, neuroscientific, psychological, historical and ethnohistorical constructions. In the conclusions, we stand out the heuristic value of the category general historical forms of personality, for the development of psychohistory, psychology, and social scientist based neurosciences.
\end{abstract}

Keywords: General historical forms of personality, Human essence, Personality, Psychohistory, Neurosciences, Ethnohistory, Historic duality.

\footnotetext{
1 Docente de la Unidad de Postgrado de Psicología en la Universidad Nacional Mayor de San Marcos, Lima, Perú. E-mail: santiagoparedesruiz@yahoo.com
} 


\section{INTRODUCCIÓN Y OBJETO DE ESTUDIO}

La mente humana, o mejor dicho la conciencia, es la gran concreción que desarrollan las relaciones sociales y la información social al codificarse éstas en el neocórtex humano (el cerebro más evolucionado o nuevo), ya prefigurado evolutivamente para tal fin, desarrollando así materialidad conciente. La conciencia es en última instancia el reflejo psíquico de la relación actuante entre la individualidad humana y la realidad social, el nivel del desarrollo evolutivo más avanzado de dos grandes formas materiales del mayor nivel de complejidad: la sociedad y la neocorteza (Ortiz, 1994, 1997, 2004). No sorprenderá entonces que al momento de nacer el individuo humano contenga ya preformadas infinitas posibilidades de configuración singular y divergente.

Que a la vez que diferencias, existan semejanzas entre grupos de personas, estará estrechamente relacionado con las regularidades estructuradas en la vida social. Todos somos parte de una cultura, de una civilización, de una educación, de un determinado tipo de familia, de una lengua, de una clase, de un aprendizaje, del sentimiento y espíritu de una época, de determinados conocimientos, valores, creencias, principios, etc. Formas generales de la materialidad social, formas generales de la evolución histórica, formas generales de la información social y de las relaciones sociales, todo ello concretizándose en formas histórico generales de la personalidad.

En la presente investigación se plantea que las formas histórico generales de la personalidad son las regularidades generales que en determinadas condiciones históricas establecen las relaciones sociales y la información social, en determinados individuos concretos y que éstos interiorizan a partir de los medios e instrumentos que dichas relaciones y que dicha información establece. Su punto de partida es la determinación epigenética que traen al momento de ser concebidos como seres humanos y su base de desarrollo son dichas regularidades generales que encuentra al momento de iniciar su constitución como persona y las que en última instancia lo determinan socio cinéticamente. Doble determinación en su doble constitución personal: por un lado el de su generalidad y por otro el de su individualidad. Su dinámica está establecida por el tipo y el carácter de las relaciones que interioriza durante su actividad y a lo largo de su biografía personal. Su comprensión dependerá también del conocimiento que tengamos de su esencia que, a decir del filósofo francés Lucien Sève (1972), se encuentra excentrada al individuo, estableciendo relaciones de determinación funcional, o mejor dicho, relaciones de determinación multidialécticas.

Las formas histórico sociales particulares de la persona serán entonces las peculiares, inigualables e infinitas estructuras activas que desarrolla un individuo social concreto en los irrepetibles espacios y tiempos biográficos personales. Son sistemas individuales de configuración histórico social de la personalidad. Expresan el mayor nivel de singularidad y manifestación concreta. Sus regularidades generales se expresan a través de sus peculiaridades y singularidades concretas. También expresa regularidades donde lo probable se ajusta en lo cambiante. En determinadas condiciones históricas, las formas particulares participan y se integran en las formas histórico generales, en su respectiva clase social, en los modos de producción histórico sociales, en el respectivo proceso macro y micro evolutivo. Esta es parte esencial del estudio psicohistórico. 
Recogiendo la trayectoria que desarrollaron diferentes temáticas de los estudios psicohistóricos (ver Pinillos, 2005), se reconoce que la psicohistoria es parte esencial de la psicología científica en una nueva manera de ver a los hombres, siguiendo métodos y enfoques que superan la linealidad mecánica y las reducciones cuantitativitas.

Así concebida, la psicohistoria es ciencia social, ciencia histórico social de los patrones y regularidades generales de la actividad psíquica conciente. Su método, siguiendo un análisis holístico multinivel, destaca la interpenetración y unidad de cuatro planos: el filosófico, el científico general, el científico específico (Academia de Ciencias de Cuba, 1981) y el método lógico-conceptual. Ellos se interpenetran ascendente y descendentemente. El nivel superior es el método filosófico dialéctico materialista, entendiendo a éste como el sistema de procedimientos lógicos complejos orientados al descubrimiento de esencialidades generales. Su método científico general es el método cualitativo correspondiente con las investigaciones científico-sociales. Su método científico particular es el método clínico social, entendiendo a este último como el estudio del origen, evolución y concreción histórico social del objeto especial (Ortiz, 2006). Su método lógico-conceptual, por los niveles de análisis y síntesis del pensamiento, es el de ascensión cualitativa de lo abstracto a lo concreto (Tecla, 1980, Mitrofán, 1964).

\section{MÉTODO Y DISEÑO DE INVESTIGACIÓN}

En base a la integración de los niveles antes expuestos, en la presente investigación se siguió como metódica, es decir, como sistema o diseño específico de procedimientos instrumentales durante la investigación, el diseño cualitativo. Siguiendo este se analizaron y triangularon datos históricos, etnohistóricos, antropológicos, sociológicos, psicosociales y neurocientíficos de destacadas y reconocidas investigaciones. Construyendo la categoría de formas histórico generales de personalidad, se desarrolló aproximaciones conceptuales cualitativas de los grupos humanos existentes en diferentes épocas históricas del espacio histórico y social denominado Perú.

El problema de investigación planteado es el de las formas históricas de ser personas en el espacio social denominado Perú. La pregunta de investigación que surgió fue cuáles son los patrones históricos de formación de la actividad consciente de las personas en el Perú. La hipótesis estratégica y cualitativa de investigación fue evolucionando hasta precisarse en que la categoría de formas histórico generales de personalidad permiten descubrir patrones periódicos de formación de las personas. El marco teórico que se aplicó como punto de partida fue el modelo sociobiológico y neurocientífico de personalidad desarrollado por Ortiz (1994, 1996, 1999, 2000, 2002, 2004).

El método de análisis consideró como caso a los grupos socio históricos que evolucionaron en la configuración del Perú como nación en formación. Los datos se extrajeron de estudios históricos, etnográficos, antropológicos, sociológicos, neurocientíficos. El análisis de los datos se efectuó triangulando éstos y efectuando la extracción de los contenidos psicohistóricos pertinentes, integrando los aportes universales de las neurociencias y desarrollando un método deductivo de los patrones psicosociales de los grupos humanos. Para desarrollar este proceso, se fue construyendo progresivamente la categoría de formas 
histórico generales y particulares de personalidad, la que se corroboró con los datos y a la vez se aplicó en la interpretación de los eventos históricos más destacados.

La validez científica de la investigación, acorde con el diseño cualitativo, sigue el criterio de legitimación (Gonzales, 2000). Dicho criterio se plantea de manera consecuente con el enfoque epistémico cualitativo (Gonzales, 1997), concibiendo a diferencia del término validez la necesidad de alcanzar nuevas zonas de sentido y de inteligibilidad en una dialéctica aproximación a la esencia del tema de estudio, o al núcleo racional de éste (Tecla, 1980).

A diferencia de las revisiones de otras investigaciones históricas, el presente estudio desarrolla como objetivo descubrir nuevos conocimientos y categorías que alcancen una nueva perspectiva de aproximación teórico metodológica a la dinámica humana en el Perú. De allí que su lógica siga una exigencia hipotético deductiva de carácter cualitativo como modelo pertinente de investigación innovadora.

\section{EVOLUCIÓN HISTÓRICA DEL PERÚ Y FORMAS GENERALES DE LA PERSONALIDAD}

A pesar de que se empieza a denominar con el nombre de Pirú, y luego como Perú al espacio socio político que se estructurará desde la conquista, éste y especialmente sus hombres no pueden ser comprendidos sin entender cómo fueron la cultura y las características psicohistóricas de los hombres que antecedieron a la conquista, pues de dicha época es que se encuentran rasgos que perdurarán hasta la actualidad en algunas zonas del actual momento histórico. De allí que debamos remontarnos a la época prehispánica a fin de comprender los datos en su diacrónica perspectiva.

\section{Las formas históricas de ser persona en la época prehispánica}

Los estudios actuales vienen ampliando nuestra comprensión de lo que fueron las características de los diferentes horizontes prehispánicos. Así es que visiones etnohistóricas más amplias, como las de M. Rostworoswki $(1989,2004)$, permiten ver que la invasión colonizadora no fue el de una cultura superior sobre una cultura inferior -la del Tahuantinsuyu y otras- sino el de una imposición de una tecnología sobre otra.

Una de las sorpresas que se llevan los conquistadores al penetrar en el suelo incaico será la ausencia de personas aisladas, hambrientas, pobres y con miseria, ausencia de delincuencia organizada y de maltrato a la naturaleza, según refiere Garcilaso en sus Comentarios reales (2003). Y aunque ahora sabemos que en muchas luchas intestinas también se afrontaron dificultades, prima la noción de una racionalidad organizativa propia del desarrollo de una civilización industriosa (León, 1994). Dicha observación corresponderá con la existencia de estructuras sociales y económicas desarrolladas adecuadamente para satisfacer el desarrollo colectivo. Las formas de su arquitectura sumamente estructurada, de su religión pública, de su producción y de las formas de relación intersistémicas nos remiten a una característica esencial de las personas del horizonte andino: el sentimiento, razón y norma colectivista.

Formas de personalidad integradas en lazos sociales que tenían como eje la organización común. Formas de personalidad que sustentaban su existencia en el colectivismo, en las 
relaciones marcadas por exigentes normas éticas de carácter solidario, que se relacionaban con la naturaleza con fe y respeto, recogiendo de ella sus frutos. Formas de organización de la familia, del tiempo fundamental o tiempo laboral en base al sentido grupal del trabajo, tanto en hombres como mujeres y niños. Formas de organización del tiempo libre, establecidas a partir de las épocas de producción agrícolas. Formas de culto y de estructuración de su fe panteísta a partir de su unión con la naturaleza, basada en la subsistencia material que el trabajo generaba. Mucho de esto fue trastocado por la conquista, mas no perdido en el tiempo.

Los recientes descubrimientos de la ciudad más antigua de América, las ruinas de Caral, nos hacen pensar que dichas formas de estructuración de la vida social y de las formas de personalidad desarrolladas a partir de ella, no sólo se desarrollarán en el ande, sino también en la costa y que en su devenir fueron manteniendo y expandiendo las formas colectivistas de relación y producción. La tendencia observada en Caral, de aglutinamiento colectivo en torno a un sistema arquitectónico, productivo y social común, es clara.

La mayoría de las formas sociales, o los diferentes horizontes prehispánicos hasta la fecha estudiados, plantean la presencia de hombres vinculados a la tierra y su cultivo, al mar y la pesca, en general a la naturaleza como elemento no sólo productivo, sino de fe, de recreación y permanente aprendizaje colectivo (Tantaleán, 2002). Mariátegui nos señala que el vínculo hacia la tierra es no sólo económico, sino también afectivo y moral, de él el hombre extraía la savia existencial de su vida (ver 7 ensayos). Ése es uno de los primeros vínculos que rompe la conquista y al hacerlo produce un quiebre en el desarrollo de las formas personales de ser del hombre desarrollado en estas tierras.

Un elemento preincaico, que caracteriza al mismo período incaico u horizonte del Tahuantinsuyu, lo constituye el sistema de intercambio productivo basado en la reciprocidad (Rostworowski, 1989). La ausencia de un mercado de intercambio a través de una moneda y por otra parte, la existencia de grandes grupos móviles que aprovecharon los diversos pisos ecológicos fue muestra de un sistema económico y humano altamente estructurado y normativizado que, vinculado con extensas áreas productivas, desarrolló sistemas colectivistas de comunicación, intercambio, producción y socialización (Murra, 2004). Dicha colectividad era capaz de integrar grandes grupos con diversidad étnico cultural y con un sistema normativo relativamente autónomo (Mayer, 2000). Posteriormente el incanato aprovecharía e integraría este sistema en una nueva estructura de poder y organización social. A pesar de sus dificultades, este sistema, en algunas partes, logró sobrevivir hasta el virreinato, tal como lo refieren documentos de la colonia (Peace, 1995). Esta forma de configuración personal es una de las tradiciones más antiguas de los pobladores que se desarrollaron en el espacio geocultural luego denominado Perú. Es parte esencial de la tradición andina.

Otro elemento especial de análisis es el que corresponde con el lugar, papel y capacidades que desarrolló la mujer prehispánica. Ella no sólo adquiere un valor especial en los mitos fundacionales del incanato, sino que también asume un rol destacado en las múltiples actividades económicas, culturales y políticas del colectivo. Es importante rescatar que dentro del mito fundacional del Cuzco se ubica a Mama Ocllo como responsable del liderazgo religioso (Rostworowski, 2004). La mujer estará presente de manera destacada 
hasta en las insurrecciones posteriores, no sólo como un integrante más de las rebeliones, sino como personaje integrado en las decisiones. Esto no hubiera sido posible si no hubiera existido esta tradición. También existen registros de la presencia de mujeres curacas o gobernantes en regiones del norte. Los relatos históricos además refieren el papel que diversas coyas tuvieron en las revueltas, sucesiones y asaltos al poder dentro de los incas. Su actuación por tanto no fue pasiva, todo lo contrario. Esta forma activa de ser protagonista se expresaría en posteriores centurias en diversos tipos de rebeliones.

Los pocos contactos e intercambios que realizó el hombre del horizonte andino con la antigua mesoamérica les obligó a buscar entre sus propios recursos la solución a sus problemas, tal como lo refiere María Rostworowski (2004). La domesticación no sólo de los animales y de la tierra, sino también del clima y la geografía exigió entre sus capacidades el desarrollo de una férrea voluntad y autonomía. Se desarrolló también una racionalización productiva del espacio (León Caparó, 1994).

La psicohistoria en el Perú puede recoger entre una de las características neuropsíquicas más interesantes las diversas formas de instrumentalización consciente, de la acumulación y evocación de información social y cultural. Por los datos que se tienen (Rowstorowski: 2004, Pease, 1995) se sabe que al igual que en otras culturas, en el incario la información sociohistórica se acumuló en cantos y narraciones orales que desarrollaban los ayllus y las panacas a través de personas especialmente capacitadas para ello. A esto se le sumó el arte grabado en mantos (el instrumento que su producción les obligó a usar) o tablas, además de los ya conocidos códigos de los quipus (Fernández, 2001). Memoria social, instrumental y neocortical presente en especiales formas culturales y personales. Nuevamente formas colectivas y recíprocas de configuración personal.

Examinando los conceptos socioculturales de tiempo y espacio telepersonal, se encuentran interesantes características cíclicas del tiempo y de percepciones finitas del espacio. A diferencia del sentido lineal y asimétrico del tiempo que existe en la lógica actual, en la época prehispánica los esquemas conceptuales del tiempo y espacio fueron diferentes. El tiempo histórico era periodificado cíclicamente, cuasi simétricamente y por épocas símiles entre sí, los que eran susceptibles de ser reactualizados en ritos, en tradiciones orales, en augurios (Peace, 1995). Así se explicaba el pasado, presente y futuro. Las características neuropsíquicas del pensamiento temporal contenían estrechos vínculos con los ciclos naturales y productivos. Las imágenes perceptuales de los ciclos políticos integrarían estos esquemas contenidos en las racionalizaciones expresadas en los denominados mitos (como los posteriores mitos de retorno del inca, que integrarían ya nociones cristianas).

Vinculada a la estructura productiva por pisos ecológicos coexistió el esquema periespacial político, social, laboral, legal, en función al uso y a la actividad que en dichos niveles ecológicos se desarrollaron las colectividades de micro y macroetnias. Esquemas lógicos de espacios finitos de desplazamiento, diferentes a las limitaciones territoriales, fueron parte de los contenidos conscientes de las personas de esta época. Este esquema sobreviviría aún en algunas zonas del virreinato y de la república actual (León Caparó, 1994; Peace, 1995).

Las formas sociales del liderazgo y de su sucesión constituyen también ejemplos de otra visión de la organización social. A diferencia de la idea de continuidad del liderazgo por 
heredad o primogenitura, en el horizonte del Tahuantinsuyu estuvo presente la visión del liderazgo y de su sucesión por aptitud. El papel de las capacidades se expresó, por ejemplo, en la sucesión tras la muerte de Sinchi Roca, así como en otras sucesiones. También el papel de las panacas o familias con raíz o tradición de gobierno, y su importancia, fue cambiando en base a la fuerza y capacidad de sus integrantes. Los grupos organizados más que territoriales eran humanos, como el que ejercían los curacas sobre determinados grupos de comunidades, más que sobre específicos límites territoriales.

La bidimesionalidad cultural y política fue parte esencial del mundo andino, aunque por supuesto una dualidad colectivista e integracionista. Algunos estudios vienen replanteando la existencia de un solo inca o de un poder único o de un monopoder en el mundo incaico. Se plantea la posible existencia de un poder dual o de una diarquía en el Tahuantinuyu, donde habríase desarrollado en muchos momentos un inca hurin Cuzco y un inca hanan Cuzco (Rostworowski, 1989; Peace, 1995). Su confirmabilidad exigiría una repercepción del mundo político en el incanato y confirmaría una visión más colectivista y distributiva de su organización política. Esto no sería adecuadamente conocido y menos comprendido por los conquistadores, quienes traían una cosmovisión de organización política de claro sello autocrático.

Considerando que la colectividad inca logró superioridad política y militar sobre otras colectividades, como la de los chancas, o la de los huancas, se sabe que el proceso de integración fue inconcluso y conflictivo, lo que nuevamente nos trae la heterogeneidad y diversidad de sentimientos y valores especialmente frente al macro poder político del Tahuantinsuyu. En muchas macroetnias prevaleció el sentimiento y concepto de identidad regional. Primó el valor de su comunidad regional por encima del valor de la integralidad multirregional. Esto devino en regionalismos al momento de redefinirse el poder y la sobrevivencia social. Se expresaría en formas de negociación cortoplacistas y oportunistas.

Lo anterior, sin embargo, no nos inhibe de plantear a partir de los elementos comunes y dominantes cuáles fueron las características predominantes en las formas generales de personalidad. ¿Qué características esenciales encontramos entonces en la forma histórica de las personas del Tahuantinsuyu? Entre algunas fundamentales tenemos la percepción colectivista y jerárquica de su actividad, el desarrollo de una voluntad autónoma, la configuración de sentimientos y creencias vinculadas a la naturaleza y a la producción, formas de memoria colectivas orales e instrumentales, contenidos racionales cíclicos del tiempo y finitos del espacio, formas de consumo determinadas por el bien común, formas de integración basadas en la reciprocidad y la redistribución. Algunas de ellas aún perduran, aunque combinadas, como parte de la epigénesis y de la resistencia cultural.

La impresión extraña que tendrían los iniciales descubridores, y luego conquistadores, al encontrar modos diferentes de vida, fue que los "nativos" de América no eran seres humanos, sino animales o comunidades salvajes. Recordemos que tendría que ser el padre de las Casas quien defendería tiempo después la humanidad de las personas del antiguo Tahuantinsuyu. Esta visión antropocentrista de la humanidad les serviría después para justificar las diversas formas inhumanas de colonización y explotación. También les conferiría una significativa desvalorización de las culturas y de las personas de la antigua 
América, y en ella del antiguo espacio después denominado Perú. Una perspectiva que aún ahora es posible encontrar, hasta en los actuales "peruanos occidentales".

\section{Nuevas formas de personalidad en la conquista y el virreinato}

Con la conquista se hizo presente en la historia nuevas estructuras personales en pos de alcanzar dos de sus grandes ideales: uno mesiánico y otro económico. Ambos estrechamente vinculados: el cultural y el económico. A decir de Del Busto (2004), el gran principio que traían los españoles conquistadores era: "servir a Dios y hacerse rico", aunque aparentemente no en dicho orden.

El modelo de hombre que traían los españoles era el suyo. Empapados del imaginario popular del medioevo europeo tardío, identificaron en sus personas a las estructuras naturales de humanidad y de civilización. Las otras formas, allende su tradicional espacio geográfico, no correspondían con su percepción normal de ser humano o de sociedad. Los otros eran indígenas, bárbaros, animales. Su emoción religiosa era la única válida y su modo de vida el más avanzado. Su conciencia estaba determinada por motivos de aventura y ambición económica, su razón dominada por ideas antropocéntricas y su afectividad centrada en su excluyente fe cristiana. Asociadas a éstas iban los objetivos de expansión española y religiosa. La instrucción o la ética eran prescindibles. La voluntad de conquista fue la dominante. Tal fue el modelo de hombre que se avino a la conquista del reino que inicialmente denominaron Birú. La forma histórico general de ser personas que llegó fue la del ambicioso aventurero.

Iniciada la conquista se desarrolló su contraparte: la resistencia, única en América, tanto en tiempo como en dureza. Los historiadores (Del Busto, 2004, Pease, 1995) destacan la guerra de resistencia liderada por Rumiñahui y por los pueblos quechuas de Vilcabamba, de duración aproximada de 36 años. Esa fue la guerra de resistencia político militar. Más en su base se desarrolló otra: la resistencia cultural, de mayor duración y complejidad. Tanto la una como la otra son indicadores de una voluntad no adormecida y menos acabada de lucha por un modo de vida propio. Estas evidencias representan la envergadura del conjunto de estructuras psicoculturales de los incas de la resistencia, así como de sus cualidades y capacidades neuropsíquicas conscientes: sacrificada constancia, heroísmo y valor temerario, inteligencia despierta, adhesión afectiva a sus orígenes.

La heterogeneidad prehispánica fue hábilmente aprovechada por los conquistadores. Muchas comunidades creyeron ver en los nuevos guerreros su oportunidad de ascenso social, independientemente de su idealización como los nuevos Wiracochas. Así fue que una de las estrategias preferidas por los españoles fue la de hacer luchar indios contra indios. De esta manera se configuraría otra forma histórica de ser personas en el antiguo Perú: la del aliado oportunista y cortoplacista, la del negociador regionalista o individualista. Éste establecería coyunturales alianzas con el conquistador.

Con la fundación de las nuevas ciudades, con el establecimiento del nuevo orden político vecinal y estatal, con la aplicación de las normas venidas de España, con el desarrollo de nuevos intercambios y la elaboración de la moneda, con la llegada de los nuevos oficios, con el establecimiento de los nuevos usos, gestos, jerarquías, creencias, lazos y demás, 
se buscó reproducir las características de las relaciones económico sociales de la Europa medieval, se aplicó el esquema informacional que traían de sus orígenes. Los españoles de ser conquistadores pasaron a ser intermediarios coloniales del poder de la metrópoli. Se constituyeron en colonizadores y mediadores. Esto iría a desarrollar también en ellos nuevos contenidos personales. Se configurarían patrones históricos intermediarios y dependientes que progresivamente se impondrían sobre la formación personal del aventurero conquistador.

Resultado del modelo económico europeo imperante, en el virreinato se impuso el mercantilismo, centrado en el desarrollo de las fuerzas productivas vinculadas con la minería y el comercio de minerales preciosos. Poco le importó a la metrópoli el desarrollo de la agricultura o de la ganadería, menos el de la artesanía autóctona. De allí que el centro de la producción virreinal estuviera en la extracción de minerales encontrados en los andes. Su mayor expresión fue la mita. El enorme comercio exclusivista fue su asociado necesario. La agricultura y ganadería siguió en manos de las antiguas comunidades, dependientes en la nueva estructura del poder colonial. Los colonizadores mantuvieron las jerarquías nativas reenganchadas dentro del nuevo poder y de una economía centrada en la extracción de minerales, que desarrolló la mita colonial, muy distinta al trabajo comunal prehispánico. Fue una relación de explotación cuasi esclavista que permitió asegurar a la metrópoli su presencia económica y militar durante los siglos XVI y XVII. El mercantilismo alimentó entre los colonizadores el reforzamiento de su percepción del hombre andino como fuerza biológica. Nuevamente primó su visión antropocéntrica de hombre.

El hombre virreinal que mejor correspondió con este sistema fue el prototipo del modelo a reproducir. El desprecio por el trabajo manual y la sobrevaloración de la actividad burocrática y autoritaria iban a constituirse en las capacidades a formar. Los indios derrotados estaban para trabajar y los conquistadores y colonizadores para mandar. La división de capacidades alcanzó no sólo a los grupos sociales sino también a las etnias. Estos hechos muestran la configuración del proceso de la dualidad en las configuraciones históricas personales.

Surgieron las configuraciones psicosociales de clases definidas por el lugar que ocuparon en las relaciones económicas establecidas y se estructuró un estado colonial mediador del poder español. Dicho estado tuvo que satisfacer dos grandes requerimientos: los de las necesidades de la metrópoli y los de las clases establecidas en la sociedad virreinal. Ambos intereses requerían mantener sojuzgado y explotado principalmente al poblador andino. Éstos fueron los determinantes funcionales de las estructuras personales en esta época histórica.

Las formas históricas generales de ser personas se estructuran a partir de las formas históricas generales de un determinado sistema de relaciones sociales e informacionales, y las formas psicológicas de clase a partir de las regularidades tradicionales, familiares, educativas y esencialmente laborales de su clase social. Un individuo, considerando lo expuesto, desarrollará su conciencia interiorizando los instrumentos sociales de su clase, y a la vez ésta se configurará en base a un sistema general de relaciones en determinada época histórica. Por ejemplo, un individuo correspondiente al grupo de vasallos, desarrolló como parte de su conciencia de clase una actitud servil frente a sus patrones, un conocimiento de sus tareas domésticas, una voluntad dependiente de sus jefes. Mientras que un noble 
de la administración virreinal expresaba actitudes de superioridad frente a sus vasallos, conocimientos técnicos de la administración, voluntad de mando en representación del rey. Estas características psicoclasistas divergentes correspondían a las formas generales de ser personas en relación al consumo, en relación al trabajo, en relación al poder político colonial. Formas de afectividad, cognición, voluntad configuradas por la dependencia, por la explotación, por el burocratismo administrativo, por el servilismo, por las creencias punitivas, por la discriminación social, por el valor de ser intermediario y dependiente del poder trasnacional de la época.

Mientras por un lado evolucionó el sistema colonial, por otro lado evolucionó su opuesto: el rechazo. En realidad, los confines virreinales más que en la geografía social fueron definidos en los mapas ilustrados, en el papel. Muchas fueron la rebeliones sociales que en esta época cubrieron el espacio histórico que va desde el siglo XVII al siglo XVIII, aunque las más descollantes fueron las de este último. Figuras como las de Ignacio Torote (sublevado en 1737); Juan Santos Atahualpa (sublevado en 1742); Antonio Cabo, Francisco Inca, Miguel Surichac, Pedro Santos (sublevados en 1750); Tomas Catari (sublevado en 1776); José Gran Quispe Tupa Inca (sublevado en 1777); los plateros del Cuzco (sublevados en 1780); y especialmente la gran rebelión de José Gabriel Túpac Amaru rebelado el sábado 4 de noviembre de 1780. Lumbreras refiere el antecedente de alrededor de 120 rebeliones (Lumbreras, 2000).

Aunque con una aparente dificultad inicial para definir un claro proyecto político, la rebelión de José Gabriel Condorcanqui, Túpac Amaru, por el contrario, muestra una evidente voluntad de rechazo, un vínculo afectivo y cognitivo con sus orígenes culturales, una visón diferente de la historia, una identidad étnica (aunque en ella participaran diferentes razas). De qué otra manera podría apreciarse a quien se identificó ante el corregidor Areche como libertador ("Aquí no hay más culpables que tú y yo; tú por opresor y yo por libertador, merecemos la muerte").

Con la desaparición humana, más no cultural de Túpac Amaru, evolucionó el sentimiento y la motivación de lucha de los antiguos y de los nuevos peruanos. Ésta se nutriría del conocimiento moderno que surgiera en la sociedad burguesa europea y se asentaría en la progresiva crisis del sistema económico mercantil asociado al exclusivismo e intervencionismo. Estas relaciones económicas no permitían el avance de las fuerzas sociales ancladas y nacientes de América. Lo que había sido una sociedad y un estado próspero devino en su contrario, y durante el siglo XIX se gestarían movimientos anticoloniales de mayor envergadura geográfica, social, cultural, política y militar.

En cada período histórico se intersectan multidialécticamente las tendencias económicas dominantes, las estructuras de clase esenciales, los contenidos culturales predominantes. Todos ellos configuran formas históricas de ser personas que mutan y se reestructuran en las siguientes épocas. Así con el virreinato, la forma histórica del conquistador se transformó en la del colonizador y del colonizado, adquiriendo éstas nuevas propiedades, las que se asentaban sobre las antiguas. Estas regularidades personales serían el legado de la tradición española, sustentada en la conquista y el virreinato.

Parte esencial de la configuración de la época será el establecimiento de un nuevo tipo de dualidad. Una dualidad que tendría como característica nuclear la lucha, la oposición, la 
desintegración o la imposición. Dualidad y resistencia sincrética de creencias, de culturas, de relaciones, de gestiones políticas, de la normatividad y de la voluntad. Germinó y evolucionó la dualidad de opuestos en la formación de las estructuras personales.

\section{Formas histórico generales de la personalidad en la independencia y república}

En la última época del virreinato surgieron nuevas relaciones en pugna con las dominantes. La nueva globalización de aquel entonces extendería en el mundo europeizado el deseo de alcanzar el conocimiento a partir de la razón individual, la ambición de mecanismos de decisión más horizontales, la expectativa de mejores condiciones de vida, las nuevas nociones éticas de gestión social, el surgimiento de nuevos idearios y esquemas de organización mental, el desarrollo de nuevos modelos de estatus social y de desarrollo personal. El tejido social y neocortical de la época cambió surgiendo un nuevo periodo histórico de trasformaciones.

El hombre que era visto como resultado de una condición inmutable, sea divina o natural, pasó a ser visto como resultado de las condiciones sociales de su existencia. Esto hizo que el sentimiento de sumisión y la voluntad de resignación devinieran en sentimientos de insatisfacción, ideas de cambio y voluntad de renovación. Cambió el modelo de hombre. De hombre natural o divino se pasó al modelo de hombre social y actor de su destino. Surgió el protagonismo del individuo y del grupo social.

La historia muestra que paralelamente a las rebeliones andinas, desde el siglo XVIII, aparecieron las rebeliones intelectuales. Figuras como Baquíjano y Carrillo, Hipólito Unanue, Juan Pablo Vizcardo y Guzman, se expresaron y organizaron en sociedades -como la Sociedad amantes del país-, en impresos -como el Mercurio peruano-, en proclamas y llamados -como la Carta a los Españoles-Americanos-. La nueva conciencia social estaba en marcha. Ella tenía como componentes esenciales el amor por el espacio geográfico y social, el conocimiento y las destrezas de la modernidad, los principios liberales, la ambición de futuro. Constituían un nuevo tipo de persona: el intelectual criollo crítico y el caudillo rebelde frente a la tradición española. Esta forma de ser se desarrollaría en paralelo con la forma andina de crítica y rebelión. De ellas, la perspectiva del criollo es la que tendría el apoyo de sus pares en el resto de la América española.

Basadre destacará como parte del proceso independentista la presencia de grupos sociales sin identidad colectiva, sin conciencia histórica de grupo, sin integridad de intereses supraindividuales. Los niveles de estructuración de una desintegrada información social limitaron las posibilidades de confluencia personales. Esto generaría una significativa disgregación política desde el mismo momento emancipador.

La racionalidad europea moderna, la experiencia de los criollos de entonces, los intereses sociales de los nuevos burgueses, el surgimiento de un nuevo sistema económico, generaría que las clases mejor dispuestas para la independencia fueran aquellas que mejor educadas y enraizadas en la colonia vieran la oportunidad para su desarrollo socio económico. Éstas fueron esencialmente la de los criollos emergentes y emprendedores. Ellos configuraron un nuevo modelo de ser personas y lucharon por imponer su modelo a lo largo de la epopeya independentista. Fueron características neuropsíquicas de los criollos del siglo 
XIX, su pasión independentista, su racionalidad modernista, su esfuerzo combativo, su oportunismo político, su caudillismo individualista, su autoritarismo militarista. La configuración de su información neocortical integraba componentes del pasado virreinal $\mathrm{y}$ del futuro capitalista.

El desarrollo inicial de la República del Perú sintetizaría, con toda sus complejidades, las nuevas tendencias liberales de la época por un lado, la tradición colonial por otro, y las diversidades del conjunto de sistemas sociales y personales del espacio político naciente. Sobre la tradición andina y la tradición colonial española se iniciaría la tradición republicana, entendiendo tradición en el sentido mariateguista de modo de vida palpitante (Mariátegui, 1978).

La ausencia de un liderazgo ideológico, social y político homogéneo, así como los nuevos intereses externos e internos se expresó en crisis permanentes, especialmente en los momentos de recambio político. Sólo en esto se hermanó la república con el incanato. En el plano de los individuos políticos, los difíciles momentos de la república del XIX fueron evidencia histórica de la inmadurez de las clases independentistas y de la nueva forma histórica de ser personas. El nuevo momento de cambio político encontró desarmados de capacidades a los nuevos grupos protagonistas. La tarea resultó muy grande. Rebeliones y contra rebeliones acaudilladas por jefes regionales o militares fue la demostración de la anarquía socio personal. Ni siquiera la bonanza del guano y del salitre impulsó el desarrollo de una clase liberal fuerte. Continuó dominando la improvisación y el despilfarro. Así llegó la guerra del Pacífico.

Siguiendo a Basadre, se encuentra que a diferencia de la traición y el abandono que muchos grupos sociales pudientes mostraron durante la guerra con Chile, otros, especialmente la gran reserva andina y los criollos patriotas demostraron, con su espléndida entrega, la existencia de un gran sentimiento de amor y de tradicional resistencia voluntarista. Son cuantiosos los ejemplos de heroísmo anónimo expresados en la resistencia peruana frente al ejército chileno, especialmente en casi toda la región andina: las luchas de Arequipa, Pasco, Ayacucho, Junín, Huancavelica, Marcavalle, Concepción, Huànuco, Huaraz, Huamachuco, la victoria cajamarquina, las guerrillas de Ica.

Llama la atención cómo, a pesar de las grandes demostraciones de resistencia social y cultural peruana mostradas en la guerra del Pacífico, las configuraciones personales divergentes entre caudillos contribuyeron a una paz deshonrosa con Chile. Esto no alcanza a ser explicado si no se considerara la presencia de patrones personales de sobrevivencia cortoplacista y oportunista, ya mostrados desde la conquista. Ésta también sigue siendo reserva del poder antinacional. Contenidos psicosociales como la poca tolerancia a la frustración, la percepción derrotista encubierta de realismo, el egocentrismo caudillista, la ausencia de enraizamiento histórico, el sentimiento de pobresperanza aprendida, la añoranza de comodidad y confort, la dismoralidad aceptada, se hicieron notar en los negociadores de la paz con Chile.

Basadre en su detallado estudio de las actuaciones personales en la guerra del Pacífico descubre la ausencia de una identidad nacional que pudiera ser fuente de coincidencias, a pesar de todas las dificultades geográficas, sociales, militares, políticas o humanas. Sin al menos un sentimiento, saber o volición común de identidad, difícil era revertir los 
notables intereses y fuerzas externas. El Perú había quedado dividido entre proyectos, ejércitos y líderes opuestos. Una de las herencias psicosociales de la guerra con Chile fue la de una supuesta superioridad racial y cultural del chileno frente al peruano (estudio de J. Kleiber de 1978, citado por Basadre, 1983). Esta noción estuvo asociada a las visiones de razas superiores desarrolladas a partir de la adaptación por selección entre especies, emparentándose con los corolarios racistas enraizados en la teoría de Darwin. Nuevamente se generó la noción ideológica de hombre superior. Ya no de Europa, ahora proveniente del sur. Noción ya superada en la historia.

Como "el sacudimiento más tremendo que el hombre peruano sintió en el siglo XIX" fue caracterizada la guerra con Chile por Basadre (Historia de la República). Remeció todo el conjunto de la vida nacional. Ruina económica, trastrocamiento social, crisis política, depresión emocional, ideas de inferioridad, vergüenza y pobreza moral. Sin embargo, así como en toda situación-problema una persona pueda mostrar lo mejor y lo peor de sí misma, en este período los pueblos del Perú mostraron lo mejor y lo peor.

Con toda esta herencia, el Perú se enrumbó al siglo XX. En él se habría de asumir el pasivo que le dejara la pasada centuria. Fue materia de agenda del nuevo siglo la unidad geopolítica, el establecimiento del estado, el denominado problema del indio, el asentamiento y desarrollo de la cultura multiétnica, la integración con la economía mundial, la situación de las nuevas clases trabajadoras, el desarrollo de la institucionalidad política, la institucionalidad constitucional, la constitución de instituciones de defensa diplomática y militar. Y estos temas evolucionarían en los nuevos escenarios de lucha clasista y de conflicto entre los renovados intereses y poderes mundiales, en las nuevas formas de colonialismo. Inevitablemente también surgirían nuevas formas generales de ser personas.

Se inició la forma histórica de consumo capitalista y con ésta su contra parte, la forma histórica de lucha contra el capital y sus formas de alienación. En paralelo evolucionó la forma histórica de ser propietario y la forma histórica de ser trabajador, la forma de ser productor, la de ser rentista y la de ser financista. Las formas históricas de ser indio evolucionaron hacia las de ser campesino, comunero o jornalero.

La economía, la producción, la cultura, la educación, la administración, mantuvieron su estructura dual como analizara Mariátegui en sus 7 ensayos (1984). La evolución y dinámica dual mantuvo tremendos problemas de relación e integración social. La confrontación entre formalidad e informalidad en el terreno económico, la confrontación entre centralismo y regionalismo, entre extracción e industrialización, entre dominación y rebelión, entre estatización y liberalización, entre planeación y libre mercado, entre otras, fueron expresiones de las diferentes formas que desarrolló la dualidad en el Perú. Prácticamente todos estos temas se encuentran presentes en las ideas y acciones producidas en la República del siglo XX. Se configuró una estructura afectiva, cognitiva y volitiva dual de ser personas.

Aunque el mal denominado problema del indio, por su sesgado enfoque racial, empezó a tomar mayor importancia en la república del siglo XX, en su inicio prácticamente se reprodujo la tradicional intervención colonial sobre el mismo. El enfoque paternalista encubierto de proteccionismo reprodujo la esencia de la visión del antiguo poder: un hombre 
desposeído y sojuzgado que requiere ser "protegido" y otro poseedor y sojuzgador, que efectúa su "protección". La dualidad en la configuración de las personas se volvía a hacer presente en la dualidad del poder.

Salud y educación empezaron a ser derechos impostergables en el desarrollo de las personas del siglo XX. A diferencia de la visión de privilegio y de élite, que existía hasta el siglo XIX, su masificación incorporó un sentir diferente de las capacidades personales. Su expansión permitió la evolución de personalidades provenientes de las clases desposeídas y de clases intermedias. Entre ellas destacarían personas como Mariátegui, provenientes de las primeras o Haya de la Torre, de las segundas.

Ascensos y caídas de numerosas organizaciones políticas serían la muestra de las significativas dificultades de estructuración de las clases en sus luchas por el poder. Protagonismos caudillescos temporales, serían expresiones de las dificultades para darle continuidad a la estructura sociopolítica republicana (Basadre, 1983). Ejemplos como los de Leguía, Sánchez Cerro, Benavides, Prado, Bustamante y Rivero, Odría, Velasco, Morales, muestran más que alianzas volubles entre grupos económicos y partidos o militares, la carencia de una identidad social, la orfandad de un proyecto histórico, la pobreza de estructuras estables, la debilidad normativa del estado todavía incipiente. Las formas de ser personas políticas contenía dichas características y ellas les eran útiles a los nuevos poderes mundiales. Se mantuvo así la forma de servilismo colonial en una nueva estructura geopolítica.

Individuos marginales a los macrosistemas integradores era la nueva forma de individualidad y egocentrismo social que reflejaba los movimientos económicos del siglo. Ascenso y caída de economías latifundistas costeñas, aparición y sustitución de recursos naturales que mantuvieron una economía de extracción, industrias dependientes de las variaciones del mercado cada vez más global, innovación sin planificación de nuevos sistemas de comunicación terrestre, producción agrícola andina atrasada y desprotegida, instituciones financieras sin soporte ni estabilidad, aparatos administrativos ineficientes y letárgicos. Todo ello es muestra del desarrollo de un capitalismo tardío, dependiente, mediatizado, deforme, enraizado en estructuras serviles coloniales y formas colectivistas de producción resiliente. Ésta es la base sobre la que se configuraría y en la que se desarrollarían intercambios culturales de renovadas formas personales dependientes y de las otras, las rebeldes.

Los cambios demográficos del siglo XX muestran un claro exponente de crecimiento urbano determinado fundamentalmente por el significativo y continuado abandono de la producción y organización social del ande. Del $63 \%$ de presencia demográfica en las zonas rurales en 1940, se pasó al $22.7 \%$ en el 2000; y del $36 \%$ en 1940, en las ciudades, se pasó al 77.3\% en el 2000 (datos de Fernando Ponce, citados por Peace, F., 1995). Esta situación en términos etnohistóricos es el resultado de una constante desvalorización del peso cultural del hombre andino en la república. Es por otra parte en términos sociológicos un proceso de reubicación social de las colectividades del ande y de transformación de las relaciones sociales de producción; en la perspectiva antropológica es parte de un proceso de sobrevivencia y de resistencia del hombre y de sus familias, en búsqueda de mejores condiciones de salud y educación. 
En términos psicosociales, los cambios antes señalados significarán el desarrollo de nuevos contenidos perceptuales, conceptuales, de imagen, de identidad, de actuación social de grupos y clases. Este proceso visto dialécticamente no sólo produjo cambios en el campo sino también en los procesos psicosociales de las ciudades. En estas últimas se irá acentuando, en base a una pluriforme diversidad cultural, el desarrollo deforme de un capitalismo dependiente (Matos Mar, 2004).

La forma histórico general principal de ser persona en el capitalismo tiene como característica esencial su constitución como mercancía. La persona se transforma en objeto de uso y en un valor de cambio. Su sentido esencial es ser fuerza productiva mercantil alcanzando formas de alienación necesarias para la reproducción del gran capital. Su valor depende ahora del mercado en el que se vende. Su sentido personal corresponde con esta nueva motivación: estar mejor preparado para venderse, en el caso del desposeído, o para comprar y capitalizar, en el caso del poseedor. Su estructura afectiva dependerá de la satisfacción que le hayan generado su venta o la compra. Sus conocimientos se medirán por los requerimientos del capital y su correspondiente tecnología, por el lugar de sus destrezas en el mercado. Sus normas dependerán de la estructura taxativa de propiedad establecida legalmente, dependerá de las nuevas necesidades sociales. Su moral corresponderá con lo que es bueno para el voluble mercado laboral. De esta manera se tejerá su neocorticalidad consciente desde que nace hasta que muere.

De la forma principal de ser persona en el capitalismo devendrán otras subsecuentes como las formas mercantilistas de consumo, formas capitalistas de ser productivo, las formas cognitivistas de aprendizaje, las formas liberales de intercambio, las formas de status, las formas de amar y ser amado, etc. Éstas son parte de una compleja configuración de estructuras y capacidades personales.

En el Perú, la forma histórica del capitalismo se establecería sobre las formas de ser personas dependientes, dismorales, disnacionales, caudillistas, egocentristas, cortoplacistas, oportunistas. Pero también, a las formas de ser mercancía, se opondrán las personas en las que por raíz o por formación se desarrollaron como independientes, solidarias, autónomas, recíprocas, colectivistas, voluntaristas. Evidentemente se presentan innumerables formas mixtas entre ambos aspectos de la contradicción, desarrollándose un espectro muy variado de sincretismos. La tradición andina, la tradición española y la republicana se sintetizarán así en nuevas formas de unidad y lucha en el presente tiempo de existencia socio personal.

Con el advenimiento de la reflexión social sobre el modo de vida también se empezaron a plantear temas antiguos como la corrupción desde puntos de vista antropológicos (ver por ejemplo El primate responsable de Silva Santisteban, 2005), éticos (ver por ejemplo los escritos sobre ética pendiente en Kliksberg, 2005 y bioética en Lolas, 2000), y políticos (Neira, 2001), como los de corrupción y gobernabilidad. Esto plantearía el problema de las formas dismorales de ser personas a lo largo de la historia. El problema de la corrupción en todos sus niveles devino en un tema de máximo nivel nacional.

Una constante de la vida social y política republicana ha venido siendo el aprovechamiento oportunista o la evasión constante del sistema de reglas que los principales poderes y partidos plantearon seguir. Ésta es una constante en el patrón formativo general de las personas provenientes de la tradición española y de la republicana, vale decir, esencialmente de los 
aristócratas, de los gamonales, de los financistas, de los burgueses y de los criollos. Una especial característica de éstos se aprecia en la valoración complaciente que les produce la manipulación de las normas a expensas de la autoridad. Una demostración valorativa de su poder la constituye la violación de la ley y su posterior impunidad. La imposición y el abuso legal se efectúan contra el más débil. Esto ha configurado una doble moral (una para los demás y otra para el que la ejerce), o mejor precisado un déficit en la configuración integrada de los programas morales personales. Esto generaría una constante desconfianza hacia las formas legales de normar y ejecutar la ley. La neocorticalidad cerebral prefrontal se configuró de manera dual y deficitaria. Esta dismoralidad se entrecruzó con las formas personales oportunistas provenientes desde la colonia virreinal.

Hasta la estructuración de relaciones económicas capitalistas exige el desarrollo de patrones conductuales normativos claros y definidos. De allí su especial interés por "normas de juego legales claras y estables". Una de las limitaciones que algunos autores plantean para el desarrollo del capitalismo en el Perú es la falta de una estructura normativa y administrativa clara que capitalice la propiedad y el trabajo, como plantea Hernando de Soto en el Misterio del capital. Estos estudios abstractos no ven sobre qué realidad humana se busca edificar un supuesto capitalismo desarrollado. Cualquier intento de construcción de una estructura económica se realiza sobre la base de las formas personales existentes en una realidad social concreta.

Una de las muestras más palpables de la psicogénesis - génesis a partir de la actividad psíquica- de la dependencia, en la república del siglo XX, lo constituyó el proceso de endeudamiento externo. Tradicionalmente este proceso ha sido visto en su aspecto opuesto: a mayor endeudamiento mayor dependencia. Sin embargo, la presencia de clases, grupos e individuos sin autonomía, sin voluntad de empresa autogestionaria, sin programas de sostenimiento de largo aliento, sin confianza en sus propias fuerzas, contribuyó al incremento geométrico de la deuda externa. Casi todos los gobiernos echaron mano de ella, especialmente los de la segunda mitad del siglo.

Los datos de la historia del Perú y de sus miembros muestra un permanente sentimiento de insatisfacción frente a la dura e injusta realidad social y económica. Desde la época prehispánica hasta la república dicho sentimiento se ha expresado en mitos, en obras literarias, en convulsiones y revueltas sociales, en crisis políticas, en asaltos al poder, en movimientos armados. Una de las constantes de la historia de los hombres y grupos del espacio de poder es que éste es precisamente inestable, voluble, crítico. Al igual que las clases pudientes que se sustituyeron en los diferentes poderes y gobiernos echando mano de la fuerza, las clases que no alcanzaron el poder también hicieron uso de la violencia. La única diferencia es que ella es legitimizada por el vencedor en el poder. Pero ésta es parte consustancial a un estado de derecho dismoral y a todas sus clases sociales. Todos ellos son evidencia de un eje horizontal de constante insatisfacción y lucha, de proyectos socioculturales insatisfechos, de pobreza y exclusión (Comisión de la Verdad, 2004), de personas infelices, lo que no sólo refleja el cuestionamiento de las instituciones políticas, sino también de las económicas, de las culturales, de las sociales. 


\section{Economía "global", cambios en las relaciones sociales y cambios en las personas}

Con la transformación del mundo económico dominante se produjeron nuevas características, tales como: el desarrollo de relaciones capitalistas monopólicas basadas en una nueva concentración y generación de utilidades a nivel de las globales empresas de tecnologías de punta: surgió un nuevo estadio de acumulación del capital y se consolidó la forma mercantil de ser persona alcanzando un estadio transnacional (Benedetti, Galeano, 1996). Surgió el desarrollo de nuevas fuerzas productivas centradas en los avances de las tecnologías de comunicación, transportes, servicios y exploración transpersonal: apareció "el hombre informático". Se planteó la integración directa del conocimiento en el desarrollo de las modernas guerras económicas: se impuso "el imperio del conocimiento" que habría de ser modelo educativo. Surgió la necesidad de asumir las tareas de la gestión en "la sociedad post capitalista o sociedad del conocimiento (como plantearon A. Tofler o P. Druker, 2004).

Entre las principales características neuropsíquicas de las personas podemos apreciar el sentido fatalista de la nueva forma del capital y la percepción de que con el capitalismo se alcanzó el fin de la historia. A ella se sumó la imagen ilusionista del irrefrenable avance tecnológico con la idea de que "ahora todo es posible" y la ilusión del dominio total: "en una economía globalizada nadie queda al margen". Por otra parte el aceleramiento de las crisis y de las reconstrucciones financieras se expresaría en la percepción de normalidad de los derrumbes y enrumbes del capital (Chossudovsky, 2003; Soros, 1999). Aparece la noción de que la persona es secundaria, la tecnología es lo esencial: la tecnología al mando. Se consolidó una tradicional forma de dividir a los hombres, unos para dirigir y otros para producir o reproducir. La formación educativa centrada en el nuevo modelo de racionalismo vino gestando la presencia de personas tecnocognitivas, o centradas en el conocimiento de la tecnología, de personas disafectivas, es decir con desorganización y déficits formativos de la afectividad (ver datos de estudios epidemiológicos de salud mental del 2002 y 2003 del Instituto Honorio Delgado-Hideyo Noguchi), de personas dismorales, es decir con un desarrollo moral deficitario y anómalo.

Características como las antes descritas se vienen consolidando en la formación de nuevas destrezas y habilidades configuradas a partir de los instrumentos tecnológicos: capacidades tecnológicas valoradas por encima de las humanísticas. A lo cognitivo se necesitó integrar nuevos patrones de moralidad con un nuevo sentido de "lo bueno": nuevos usos del tiempo, nuevos valores educativos, familiares, industriales. Ser bueno en este contexto se determina por el valor que brinda el mercado donde la calidad asume un sentido y dimensión singular. La calidad de la reproducción capitalista aparece como nuevo poder de la gestión del conocimiento. Aparece una nueva versión del hombre-máquina: más lejos de los hombres y más cerca del objeto. La evolución cortical se mide en base al cronómetro del desarrollo del gran capital.

Sin embargo, a pesar de las tendencias dominantes, se encuentran también presentes nuevas configuraciones discrepantes, tales como las formas de convicción y organización ecológicas, éticas, culturales, técnicas, artesanales. Nuevas capacidades de resiliencia, de empoderamiento, de organización, de participación, de transformación social. Junto a las tendencias dominantes se encuentran presentes las de hombres constructores, optimistas, justos, solidarios, en un proceso de cambio global. 
Aun en el actual período histórico coexisten diferentes y divergentes patrones y configuraciones macro personales. Mientras por un lado se desarrollan formas consumistas propias del capitalismo, por otro lado se expresan casi autónomamente formas colectivistas en las comunidades campesinas serranas (Mayer, 2000). Éstas últimas ocupan espacios económicos y desarrollan mecanismos políticos, organizativos, normativos propios, independientes del estado. Y con estos patrones, muchos de sus integrantes migaron hacia las ciudades más importantes en diferentes períodos históricos (Matos, 1977). Con sus costumbres, creencias, estrategias, ritmos, hábitos, mitos, ellos disputan y se desarrollan, en muchos aspectos, al margen del estado, aun en las ciudades, desarrollando un aparente desborde social (Matos, 2004). Desde el enfoque de la presente investigación se producen relaciones multidialécticas de unidad y lucha, que puede ser de supeditación, de oposición, de negación, de superación o de confrontación. Coexisten multidialécticamente diferentes determinaciones en sistemas paralelos de síntesis.

\section{CONCLUSIONES}

A lo largo de la investigación se encuentra que las relaciones sociales, la información social y las estructuras culturales de determinados períodos históricos configuran patrones generales de ser personas, es decir formas histórico generales de personalidad. Estas permiten comprender características longitudinales de la afectividad, cognición, moralidad de los hombres concretos. Como parte de sus configuraciones se encuentra mecanismos propios de cada época al codificar o memorizar información, al representar el espacio y el tiempo, al organizarse e interactuar. Se comprenden los motivos personales de la actuación en cada momento histórico. Las formas generales de ser personas reflejan de manera viva, intrínseca los contenidos de su existencia sociopersonal.

Los diferentes períodos históricos configuraron formas de reciprocidad y colectivismo, en los horizontes prehispánicos; formas de individualismo, servilismo y dependencia en el virreinato; formas de configuración mercantilistas y neodependientes en la república. Todas ellas en interacción con formas regionalistas de identidad que dificultaron mayores niveles de integración y proyección personal. Esto estimuló el desarrollo de diferentes formas de ser personas, las que antepusieron su sobrevivencia personal o comunal frente a la integración colectiva, política o multiétnica. Como parte de su actuación se manifestaron conductas que destacan por su oportunismo cortoplacista, lo cual se puede apreciar en diferentes crisis históricas, como las de la conquista, de la emancipación, de la guerra con Chile, etc.

De una forma bidimensional de cosmovisión social en el horizonte tardío del Tahuantinsuyu, se pasó a una dualidad económica, social, cultural, normativa y política que se reflejó y retroalimentó, en y de las constituciones dualistas de las personas. Esto dio lugar a sistemas personales de disafectividad, dismoralidad, informalidad.

Desde la conquista se encuentra en las características psicohistóricas de las personas, el devenir de diferentes formas del sentimiento de insatisfacción, de frustración, de pobresperanza. Las etapas históricas muestran también patrones de conocimientos autónomos, como en la época prehispánica, y dependientes, como en diferentes épocas 
posteriores. Uno de los sistemas psicohistóricos más comprometidos fue el sistema conativo volitivo, el cual siguiendo desde la conquista un modelo externo se configuró de manera dependiente, disminuyendo la voluntad autónoma, la capacidad intrínseca de seguir normas justas. Sin embargo, el devenir de las tradiciones andina, española y republicana muestran la presencia de formas de resistencia presentes en múltiples espacios de actuación.

Coexisten por otra parte formas andinas de colectivismo autónomo que mantienen algunas de las características de organización social y productiva tradicional. Sobre las formas históricas más generales se desarrollan características singulares de la denominada globalización postmodernista, la que desarrolla un modelo de hombre tecnocognitivo, el que se mimetiza con las estructuras personales propias del devenir histórico de los países subdesarrollados o dependientes.

Los hallazgos teóricos del presente trabajo permiten explicar formas específicas de producción de personas que se producen en determinados tiempos históricos. Coexisten en la pluriforme psicohistoria de las personas las antiguas con las nuevas formas de producir y producirse, de dominar y ser dominado, de sentir, de organizarse, de rebelarse, de vivir y formarse.

\section{REFRENCIAS BIBLIOGRÁFICAS}

1. Academia de ciencias de Cuba y Academia de Ciencias de la URSS (1981). La dialéctica y los métodos científico generales de investigación. La Habana: Editorial de Ciencias Sociales.

2. Basadre, J. (1983). Historia de la República. 7. ${ }^{\text {a }}$ edición. Lima: Editorial Universitaria.

3. (1984). Perú: Problema y posibilidad. Lima: COTECSA.

4. Benedetti, M. Galeano, E. Chomsky, N. Dieterich, H. y otros (1996). Crítica de la modernidad y la globalización. Lima: Ediciones del Salmón.

5. Baudin, L. (1978). El imperio socialista de los incas. Santiago de Chile: Zigzag.

6. Cayo Córdova, P. (2004). "República”, En Enciclopedia Temática tomo III. Lima: El Comercio.

7. Comisión de la Verdad (2004). Atún Willacuy. Lima.

8. Del Busto, J. (2004). “Conquista y Virreinato”, En Enciclopedia Temática tomo II. Lima: El Comercio.

9. Comte, A. (2002). Curso de filosofía positiva. Barcelona: Folio.

10. Chossudovsky, M. (2003). Globalización de la pobreza. Buenos Aires: Siglo XXI Editores.

11. Drucker. P. (2004). La sociedad post capitalista. Bogotá: Grupo Editorial Norma.

12. Fernández L., M. (2001). Escritura incaica. Lima: Universidad Nacional Federico Villarreal, Editorial Universitaria. 
Psicohistoria y formas histórico generales de la Personalidad en el Perú

13. Garcilaso de la Vega, I. (2003). Comentarios reales de los incas. Lima: Fondo Editorial Cultura Peruana.

14. Gómez de Silva, G. (1995). Breve diccionario etimológico de la lengua española. México: FCE.

15. González Rey, F. (1997). Epistemología cualitativa y subjetividad. La Habana: Pueblo y educación.

16. González Rey, F.(2000). Investigación cualitativa en psicología. México: International Thomson Editores.

17. Instituto Especializado de Salud Mental “Honorio Delgado - Hideyo Noguchi” (2003). "Estudio Epidemiológico de Salud Mental". En Anales de Salud Mental vol. XIX, Nos. 1 y 2, Editor Javier Saavedra Castillo. Lima, Perú.

18. Kiksberg, B. (2005). La agenda ética pendiente de América Latina. Buenos Aires: FCE.

19. Larson, E., (2007). Evolución. La asombrosa historia de una teoría científica. Buenos Aires: Sudamericana.

20. León Caparó, R (1994). Racionalidad andina en el uso del espacio. Lima: BCR, Fondo Editorial: Lima.

21. Leontiev, A.N. (1984). Actividad, conciencia y personalidad. México: Cartago.

22. Lertora, Adolfo (1974). Estructura del Hombre. Buenos Aires: Sílaba.

23. Lolas, F. (2000). Bioética y antropología médica. Mediterráneo: Santiago de Chile.

24. Lumbreras, L. (2000). "Evolución del poder en los andes". En: El Perú en los albores del siglo XXI-4. Lima: Fondo Editorial del Congreso del Perú.

25. Luria, (1974). El cerebro en acción. Barcelona: Fontanella.

26. Makowski, K. (2004). Primeras civilizaciones, En Enciclopedia Temática tomo IX. Lima: El Comercio.

27. Mariátegui, J.C. (1978). Peruanicemos al Perú. Lima: Amauta.

28. Mariátegui, J.C. (1984). 7 ensayos de interpretación de la realidad peruana. Lima: Amauta.

29. Mariátegui, J.C. (1988). Temas de Educación. Lima: Amauta.

30. Mariátegui, J.C. (1990). Ideología y Política. Lima: Amauta.

31. Matos Mar, J. (1977). Las barriadas de Lima 1957. Lima: IEP.

32. Matos Mar, J. (2004). Desborde popular y crisis del estado. Lima: IEP.

33. Mayer, Rostworowski, Macera y otros (2000). El Perú en los albores del siglo XXI. Lima: Fondo Editorial del Congreso del Perú. 
34. Mitrofan, Alexeiev (1964). Dialéctica de las formas del pensamiento. Buenos Aires: Platina.

35. Murra, J. (2004). El mundo andino. Población, medio ambiente y economía. Lima: IEP.

36. Neira, H. (2001). El mal peruano. 1990-2001. Lima: SIDEA.

37. Ortiz C., P.(1994). El sistema de la personalidad. Lima: Orión.

38. Ortiz C., P. (1996). Introducción a la medicina clínica. I El examen clínico esencial. Lima: Universidad Nacional Mayor de San Marcos.

39. Ortiz C., P. (1997). La formación de la personalidad. Lima: Dimaso.

40. Ortiz C., P. (1998b) El nivel consciente de la memoria. Lima: Fondo Editorial de la Universidad de Lima.

41. Ortiz, C., P. (1999) El examen neurológico integral. Lima: Fondo Editorial de la Universidad Nacional Mayor de San Marcos.

42. Ortiz C., P. (2000). Psicobiología humana. Introducción a una psicobiología del hombre. Lima: Universidad de Lima:

43. Ortiz, C., P. (2004). El nivel consciente de la Actividad Personal. Lima: Universidad Nacional Mayor de San Marcos.

44. Ortiz, C., P. (2006). El examen psicológico integral. Lima: Fondo Editorial de la Universidad Nacional Mayor de San Marcos.

45. Pajuelo, R. Sandoval, P. (2004). Globalización y diversidad cultural. Lima: IEP.

46. Pease, F. (1995). Breve Historia Contemporánea del Perú. México: FCE.

47. Pinillos, J.L., Jodorowsky, A. y otros (2005). Psicópolis. Paradigmas actuales y alternativos en la psicología contemporánea. Barcelona: Kairós.

48. Rostworowski de Diez Canseco, M.(1989). Historia del Tahuantinsuyu. Lima: IEP.

49. Rostworowski de Diez Canseco, M.(2001). Obras Completas I. Pachacutec. Lima: IEP.

50. Rostworowski de Diez Canseco, M.(2004). "Incas”. En Enciclopedia Temática tomo I. Lima: El Comercio.

51. Sagan, C. (1979). Los dragones del edén. Barcelona: Grijalbo.

52. Sève, L.(1972). Marxismo y Teoría de la Personalidad. Buenos Aires: Amorrortu editores.

53. Silva Santistevan, F. (1982). Historia del Perú. Lima: Ediciones Buho.

54. Silva Santistevan, F. (2005). El primate responsable: antropobiología de la conducta. Lima: Fondo Editorial del Congreso del Perú. 
Psicohistoria y formas histórico generales de La Personalidad en el Perú

55. Soros, G. (1999). La crisis del capitalismo global. Barcelona: Plaza Janés.

56. Soto, H. (1987). El otro sendero. Lima: ILD.

57. Soto, H. (2000). El misterio del capital. Lima: El Comercio.

58. Tantaleán A., J. (2002). PIRV, espacio, economía y poder (12,00 a.C.-1572 d.C.). Lima: Fondo Editorial del Congreso del Perú.

59. Tecla, A. (1980). Metodología en las ciencias sociales. México: Taller Abierto.

60. Ursul. (1972). El concepto de información. Montevideo.

61. Vigotsky, L. S.(1983). Pensamiento y lenguaje. Buenos Aires: La Pléyade.

62. Vigotsky, L.(1987). Historia del desarrollo de las funciones psíquicas superiores. La Habana: Científico Técnica.

63. Watanabe, S. (1983). "La información". En: Barhillel, Y. y otros (eds.). El pensamiento científico. Conceptos, avances y métodos. Madrid: UNESCO.

64. Wyn Davies, M. (2005). Antropología para principiantes. Era Naciente: Buenos Aires. 